\title{
Are there geographical disparities in access to liver transplantation in Atlantic Canada?
}

\author{
Paul Douglas Renfrew BSc MD MSc FRCSC ${ }^{1,2}$, Michele Molinari MD MSc FACS ${ }^{1}$
}

\begin{abstract}
PD Renfrew, M Molinari. Are there geographical disparities in access to liver transplantation in Atlantic Canada? Can J Gastroenterol 2012;26(10):705-710.
\end{abstract}

OBJECTIVE: To characterize the patient population served by Atlantic Canada's Multi-Organ Transplant Program liver transplant service over the first five years of activity in its current iteration.

METHODS: Data from a prospective institutional database, supplemented by retrospective medical record review, were used to identify and characterize the cohort of patients assessed for consideration of first liver transplant between December 1, 2004 and December 1, 2009.

RESULTS: In the five-year period after reactivation, the program assessed 337 patients for first liver transplant. The median age at referral for this group of 199 men $(59.0 \%)$ and 138 women (41.0\%) was 56.1 years (range 16.3 to 72.3 years). The leading three liver diseases indicating liver replacement were alcohol-related end-stage liver disease $(20.5 \%)$, hepatocellular cancer $(16.6 \%)$ and hepatitis C-related end-stage liver disease (14.0\%). When evaluated according to provincial population-standardized incidence, significant differences in the incidence of liver transplant assessment among the four Atlantic Canadian provinces were found (per 100,000 inhabitants: Nova Scotia 19.8, New Brunswick 13.0, Newfoundland and Labrador 9.1 and Prince Edward Island 11.0; Fisher's exact $\mathrm{P}<0.001$ ). Of the 337 individuals who began the assessment process, $153(45.4 \%)$ were assigned to the wait list. The probability of an individual being assigned to the wait list was not found to differ according to province of residence (Nova Scotia 45.3\%, New Brunswick 40.0\%, Newfoundland and Labrador 58.7\% and Prince Edward Island 40.0\%; Fisher's exact P=0.206).

CONCLUSIONS: The analysis suggests that there are geographical disparities in access to liver transplantation in Atlantic Canada. These disparities appear to be related to factors that precede the transplant assessment process.

Key Words: Demography; Health services accessibility; Liver transplantation

$\mathrm{O}$ July 3, 1985, the Multi-Organ Transplant Program, based in Halifax, Nova Scotia (NS), began providing adult liver transplant service for residents of the four provinces of Atlantic Canada: NS; New Brunswick (NB); Newfoundland and Labrador (NL); and Prince Edward Island (PE). In May 2001, the program's Liver Transplant Service suspended its surgical activity due to lack of sufficient surgical manpower. With the acquisition of a new transplant surgeon in July 2004, preparations were made to reactivate the service and, subsequently, on December 1, 2004, the Multi-Organ Transplant Program reassumed responsibility for all aspects of adult liver transplantation for Atlantic Canada. Five years after reactivation, a broadbased study was undertaken, which included in its objectives the characterization of the liver transplant service population and the evaluation of its pre- and post-transplant outcomes. The present report describes the cohort of individuals who were assessed for first liver transplant during the five-year period, and characterizes their

\author{
Y a-t-il des disparités géographiques dans l'accès \\ aux transplantations hépatiques en Atlantique \\ Canada?
}

OBJECTIF : Caractériser la population de patients desservie par le service de transplantation hépatique du programme de transplantation d'organes de l'Atlantique au cours des cinq premières années d'activités sous sa forme actuelle.

MÉTHODOLOGIE : Les chercheurs ont utilisé les données tirées de la base de données prospective d'un établissement, complétées par une analyse rétrospective des dossiers médicaux, pour repérer et caractériser la cohorte de patients évalués en vue de subir une première transplantation hépatique entre le $1^{\text {er }}$ décembre 2004 et le $1^{\text {er }}$ décembre 2009.

RÉSULTATS : Pendant la période de cinq ans suivant sa réactivation, le programme a permis d'évaluer 337 patients en vue d'une première transplantation hépatique. Ce groupe de 199 hommes (59,0 \%) et de 138 femmes $(41,0 \%)$ avait un âge médian à l'aiguillage de 56,1 ans (plage de 16,3 à 72,3 ans). Les trois principales maladies hépatiques indicatrices d'une transplantation hépatique étaient la maladie hépatique alcoolique en phase terminale $(20,5 \%)$, le cancer hépatocellulaire $(16,6 \%)$ et la maladie hépatique en phase terminale liée à l'hépatite C (14,0\%). Lorsqu'on l'évaluait d'après l'incidence standardisée dans la population provinciale, on constatait des différences significatives de l'incidence d'évaluations de transplantation hépatique dans les quatre provinces canadiennes de l'Atlantique (sur 100000 habitants : Nouvelle-Écosse 19,3, NouveauBrunswick 12,7, Terre-Neuve-et-Labrador 9,0 et Île-du-Prince-Édouard 10,9; $\mathrm{P}<0,001$ [test exact de Fisher]). Sur les 337 personnes qui ont amorcé le processus d'évaluation, 153 (45,4\%) ont été placées sur la liste d'attente. On a constaté que la probabilité qu'une personne soit placée sur la liste d'attente ne différait pas selon la province de résidence (Nouvelle-Écosse 45,3\%, Nouveau-Brunswick 40,0 \%, Terre-Neuve-et-Labrador 58,7 \% et Île-du-Prince-Édouard 40,0 \%; P=0,206 [test exact de Fisher]).

CONCLUSIONS : L'analyse indique qu'il existe des disparités géographiques dans l'accès aux transplantations hépatiques en Atlantique Canada. Ces disparités semblent liées aux facteurs qui précèdent le processus d'évaluation des transplantations.

assessment process and outcome. Results from secondary analyses of candidates assigned to the wait list and those who received a transplant during the study period, which were relevant to the principle analysis, are also reported.

\section{METHODS}

Before initiation of the study, the protocol was approved by the Capital Health Research Ethics Board. The study cohort was delineated from the prospective Multi-Organ Transplant Program's database, which records demographic and clinical information on all patients referred to the liver transplant service for consideration of liver replacement. These data were supplemented by retrospective medical record review.

The study cohort was comprised of all individuals who were referred, and began assessment for, first liver transplant between December 1, 2004 and December 1, 2009. Individuals who died before initiation of

${ }^{1}$ Department of Surgery, Dalhousie University, Halifax, Nova Scotia; ${ }^{2}$ Department of Surgery, The Moncton Hospital, Moncton, New Brunswick

Correspondence: Dr Paul Douglas Renfrew, Suite 106A, 1600 Main Street, Moncton, New Brunswick E1E 1G5. Telephone 506-857-5899,

fax 506-857-5903, e-mail p.d.renfrew@dal.ca

Received for publication January 18, 2012. Accepted April 25, 2012 


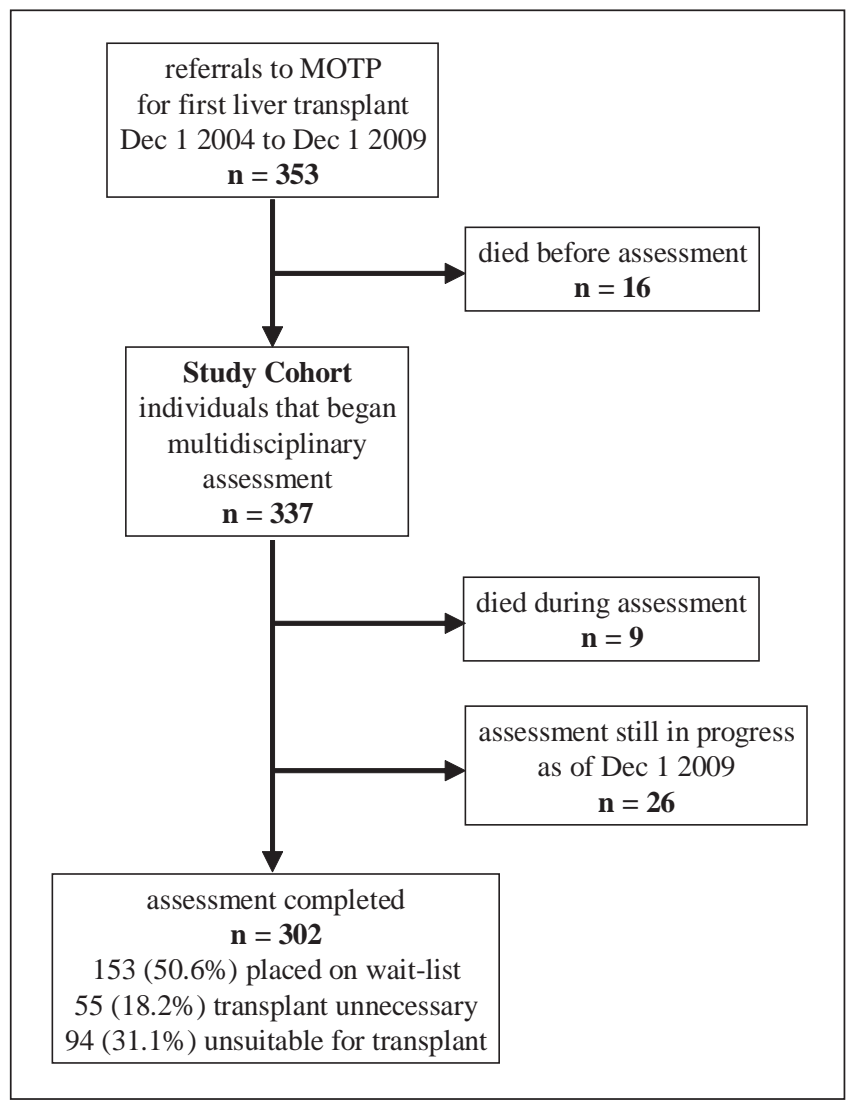

Figure 1) Study cohort derivation and outcomes. Dec December; MOTP Multi-Organ Transplant Program

candidacy assessment were excluded, as were individuals who were assessed for repeat liver transplant. The wait list and transplant cohorts on which the secondary analysis were based were composed of, respectively, all individuals assigned to the wait list for receipt of first liver transplant, and all individuals who received a primary liver transplant between December 1, 2004 and December 1, 2009.

Measured variables included the following: sex, age at referral, province of residence, primary liver disease indication for transplant and secondary liver disease(s). Assessment time was measured from referral date until date of official candidacy decision, death during assessment (censored) or December 1, 2009 (censored). Populationstandardized incidences were calculated based on provincial populations from the 2006 Canadian census and are expressed per 100,000 persons (1). Ninety-five per cent Cls for these point estimates were calculated using Wilson's formula for a binomial, as recommended by Rothman $(2,3)$.

All statistical analyses were performed using Stata/IC 11 software (StataCorp, USA). Categorical variables are expressed as frequencies and percentages. For continuous variables, the median was used as the measure of central location, and the interquartile range (IQR) and/or range as the corresponding measure of variation. The Kaplan-Meier, product limit, method for censored time-to-event data was used to describe assessment time to completion.

The Fisher's exact test was used for statistical comparisons between categorical variables. Univariable analysis of assessment time-to-completion, wait-list survival and wait time to transplant was performed by comparison of the Kaplan-Meier estimates of the survival function between groups, defined according to province of residence, using the log-rank test. Multivariable Cox proportional hazards regression was used to generate covariate-adjusted HRs to describe the association between province of residence and wait-list survival and wait time to transplant. All tests of hypothesis were two-sided and a $5 \%$ probability of type I error was the threshold for significance.
TABLE 1

Description of the cohort of 337 individuals referred to the Multi-Organ Transplant Program Liver Transplant Service between December 1, 2004 and December 1, 2009, who began multidisciplinary assessment of candidacy for first liver transplant

\begin{tabular}{ll}
\hline Variable & \\
\hline Sex & $199(59.0)$ \\
Male & $138(41.0)$ \\
Female & $56.1(16.3-72.3)$ \\
Age, years, median (range) & $56.0(20.6-72.3)$ \\
Male & $56.6(16.3-70.2)$
\end{tabular}

Top 10 primary liver diseases

1. Alcohol-related end-stage liver disease $69(20.5)$

2. Hepatocellular cancer 56 (16.6)

3. Hepatitis C-related end-stage liver disease 47 (14.0)

4. Primary biliary cirrhosis $34(10.1)$

5. Primary sclerosing cholangitis $27(8.0)$

6. Cryptogenic cirrhosis $22(6.5)$

7. Autoimmune hepatitis 19 (5.6)

8. Non-alcohol-related steatohepatitis $19(5.6)$

9. Acute liver failure 11 (3.3)

10. Polycystic liver disease $5(1.5)$

Other diagnoses $28(8.3)$

Province of residence

Nova Scotia $181(53.7)$

New Brunswick 95 (28.2)

Newfoundland and Labrador $\quad 46$ (13.6)

Prince Edward Island 15 (4.5)

Data presented as $n$ (\%) unless otherwise indicated

\section{RESULTS}

From the date of its reactivation (December 1, 2004), until December 1, 2009, the Multi-Organ Transplant Program's liver transplant service assessed 337 individuals for receipt of first liver transplant (Figure 1). The characteristics of this cohort are summarized in Table 1 . The three leading primary liver diseases indicating transplant were alcoholrelated end-stage liver disease (20.5\%), hepatocellular cancer $(16.6 \%)$ and hepatitis C-related end-stage liver disease (14.0\%). In 50\% of the individuals with hepatocellular cancer (28 of 56), the underlying endstage liver disease was due to chronic hepatitis $\mathrm{C}$ infection. Thus, the prevalence of hepatitis C-related liver disease in the cohort of referrals assessed was $22.3 \%$ (75 of 337). The cholestatic liver diseases, primary biliary cirrhosis and primary sclerosing cholangitis, were the primary indications for transplant assessment in 18.1\% (61 of 337) of the cohort.

Not included in the assessment cohort were 16 individuals who were referred during the five-year period, but died before assessment could be initiated. As such, information on this group of 16 preassessment mortalities is incomplete and the quality of the data may be suspect. It must also be recognized that, because they had not been assessed, their actual candidacy for transplantation is unknown. Nevertheless, some exploratory observations on this group may be informative. This group of 12 males and four females did not appear to differ from the cohort who began transplant assessment according to age, liver disease etiology or province of residence (data not shown). All 16 preassessment fatalities had a chronic liver disease listed as the primary indication for transplantation. The cause of death was known for only six of the 16 referrals, five of which were due to end-stage liver disease-related complications and, one patient who had been referred very proactively with slowly progressive end-stage liver disease, died suddenly from an acute cardiac event just weeks before transplant assessment was to have started. Laboratory data sufficient for calculation of Model for End-stage Liver Disease score 
(United Network for Organ Sharing modification) were available for 12 of the 16 referrals for which the median score was 18.5 (range 7 to 38). By comparison, the median score for the 121 individuals with end-stage liver disease who were assigned to the wait list during the fiveyear study period was 13 (range 6 to 33). The relatively high level of illness acuity of the individuals who succumbed before the initiation of transplant assessment, coupled with the observation that the median time between referral and death for this group of 16 was 17.5 days (interquartile range 2.5 days to 33 days; range 0 to 585 days), suggests that these individuals were either suffering from rapidly progressive endstage liver disease or that they were referred late in the course of their disease process.

The assessment outcomes for the study cohort, as of December 1, 2009, are summarized in Figure 1, and the Kaplan-Meier estimate of assessment time to completion is presented in Figure 2. Of the 337 individuals who began multidisciplinary transplant assessment, $302 \mathrm{com}$ pleted the process, 26 were still in progress at the end of the study period and nine died during their candidacy assessment. For eight of the nine individuals who died, the indication for transplantation was a chronic liver disease and complications of end-stage liver disease were the direct cause of death for seven, while an acute myocardial infarction was the principle cause of death in one. The other individual who died during the assessment process experienced subacute liver failure due to autoimmune hepatitis, with their terminal event being an acute myocardial infarction. For the 302 individuals who completed the assessment process, approximately one-half $(50.6 \%)$ were deemed to be suitable candidates and were assigned to the wait list, almost onethird $(31.1 \%)$ were deemed to be unsuitable for transplantation and transplantation was believed to be unnecessary in $18.2 \%$.

\section{Geographical comparisons}

The province of residence for the 337 referrals assessed over the fiveyear period is summarized in Table 1. Relative to their proportional contribution to the 2006 census of Canada population of Atlantic Canada (total 2,284,779), residents of NS appeared to comprise a greater proportion of the cohort than might be expected. This led to an analysis of the population-standardized incidence of transplant assessment according to province of residence, the results of which are summarized in Table 2. As shown, the population-standardized incidence of referrals assessed differed significantly (Fisher's exact $\mathrm{P}<0.001$ ) across the four provinces. Based on the results of this analysis, it appeared that, relative to NS, residents of the other three Atlantic provinces were $34.3 \%$ (NB incidence ratio $13.0 / 19.8=$ 0.657 ) to $54.0 \%$ (NL incidence ratio $9.1 / 19.8=0.460$ ) less likely to be assessed for liver transplant. The secondary analyses showed these differences were carried over to the population-standardized incidences of wait list assignment and liver transplantation, as shown in Table 2. Of note, the persistence of disparities in these two subsequent outcomes implies that the interprovincial differences in liver transplant candidacy assessment are not simply a function of relative over-referral of individuals from NS.

Once assessment had begun, assessment time to completion was not found to differ according to province of residence (Kaplan-Meier

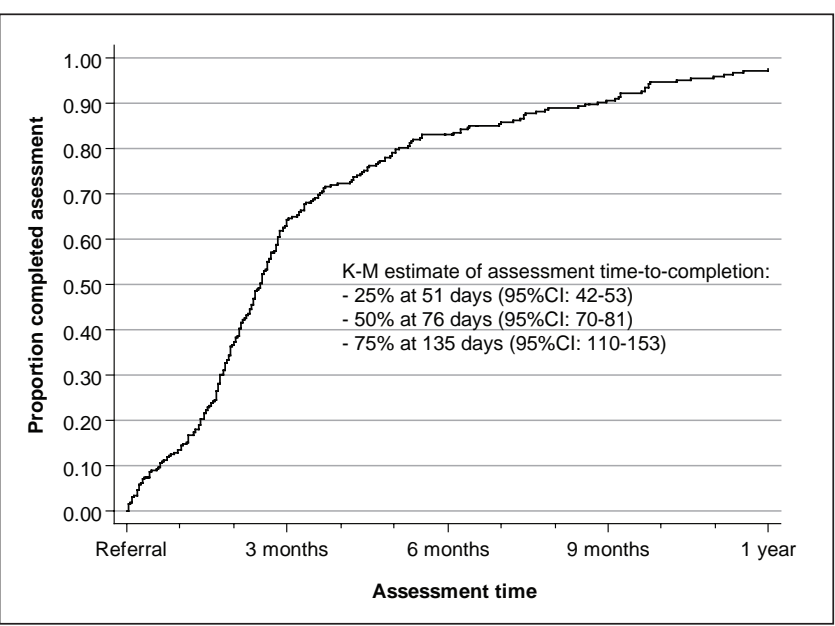

Figure 2) Description of multidisciplinary liver transplant assessment time to completion for the five-year cohort $(n=337)$. K-M Kaplan-Meier

estimate of median days to assessment completion and 95\% CI: NS 73 days [64 to 81]; NB 80 days [65 to 98]; NL 76 days [62 to 87]; PE 77 days [ 45 to 86 ]; $\log$ rank $\mathrm{P}=0.594$ ). Additionally, the probability of an individual being assigned to the wait list was not found to differ according to province of residence (NS 45.3\% [82 of 181]; NB 40.0\% [38 of 95]; NL 58.7\% [27 of 46]; PE 40.0\% [six of 15]; Fisher's exact $\mathrm{P}=0.206$ ). These results imply that, once assessed by the Multi-Organ Transplant Program, there did not appear to be any disparity in access to liver transplantation. To explore this premise further, the outcomes for the cohort of patients assigned to the wait list during the study period were analyzed.

In the five-year period between December 1, 2004 and December 1, 2009, 159 individuals were assigned to the Atlantic Multi-Organ Transplant Program's wait list for first liver transplant (153 from the referrals assessed cohort joined by six candidates who were referred and/or assessed shortly before the service was formally reactivated). By the end of the study period, only nine candidates (5.7\%) were still awaiting a donor organ, while the remaining 150 candidates had all experienced a definitive wait-list outcome. Of these 150 candidates, $105(66.0 \%)$ successfully received a liver transplant and $17(10.7 \%)$ died $(n=7)$ or were removed from the wait list due to terminal liver disease $(n=10)$ (for a more detailed description of this cohort and their outcomes see references 4 and 5).

The risk of wait-list failure was not found to differ according to province of residence (Fisher's exact $\mathrm{P}=0.176$ ), and ranged from: $7.1 \%$ (two of 28 candidates) for NL; 8.2\% (seven of 85) for NS; $15.0 \%$ (six of 40 ) for NB; and $33.3 \%$ (two of six) for PE. Univariable wait-list survival analysis supported this finding $(\log$ rank $\mathrm{P}=0.275)$. Because the wait-list survival of this cohort was known to be significantly influenced by Model for End-stage Liver Disease score at the time of waitlist assignment and $\mathrm{ABO}$ blood group status, multivariable survival

\section{TABLE 2}

Multi-Organ Transplant Program Liver Transplant Service: number of referrals assessed, assigned to wait list and transplanted according to province of residence, December 1, 2004 to December 1, 2009

\begin{tabular}{|c|c|c|c|c|c|c|c|c|c|c|}
\hline \multirow[b]{2}{*}{ Province } & \multirow{2}{*}{$\begin{array}{c}2006 \text { census } \\
\text { population, } \\
n(\%)\end{array}$} & \multicolumn{2}{|c|}{ Referrals assessed } & \multirow[b]{2}{*}{ Exact $P$} & \multicolumn{2}{|c|}{ Assigned to wait list } & \multirow[b]{2}{*}{ Exact $P$} & \multicolumn{2}{|c|}{ Transplanted } & \multirow[b]{2}{*}{ Exact $\mathrm{P}$} \\
\hline & & n (\%) & $\begin{array}{c}\text { Per } 100,000 \\
\text { residents }(95 \% \mathrm{Cl})\end{array}$ & & n (\%) & $\begin{array}{c}\text { Per } 100,000 \\
\text { residents }(95 \% \mathrm{Cl})\end{array}$ & & n (\%) & $\begin{array}{c}\text { Per } 100,000 \\
\text { residents }(95 \% \mathrm{Cl})\end{array}$ & \\
\hline NS & $913,462(40.0)$ & $181(53.7)$ & $19.8(17.1-22.9)$ & \multirow{4}{*}{$<0.001$} & $85(53.4)$ & $9.3(7.5-11.5)$ & \multirow{4}{*}{0.009} & $73(57.5)$ & $8.0(6.4-10.0)$ & \multirow{5}{*}{0.001} \\
\hline NB & 729,997 (32.0) & $95(28.2)$ & $13.0(10.6-15.9)$ & & $40(25.2)$ & $5.5(4.0-7.5)$ & & $33(26.0)$ & $4.5(3.2-6.3)$ & \\
\hline$N L$ & 505,469 (22.1) & $46(13.7)$ & $9.1(6.8-12.1)$ & & $28(17.6)$ & $5.5(3.8-8.0)$ & & $16(12.6)$ & $3.2(1.9-5.1)$ & \\
\hline PE & $135,851(5.9)$ & $15(4.4)$ & $11.0(6.7-18.2)$ & & $6(3.8)$ & $4.4(2.0-9.6)$ & & $5(3.9)$ & $3.7(1.6-8.6)$ & \\
\hline Total & $2,284,779(100)$ & $337(100)$ & $14.7(13.3-16.4)$ & & $159(100)$ & $7.0(6.0-8.1)$ & & $127(100)$ & $5.6(4.7-6.6)$ & \\
\hline
\end{tabular}

NB New Brunswick; NL Newfoundland and Labrador; NS Nova Scotia; PE Prince Edward Island 


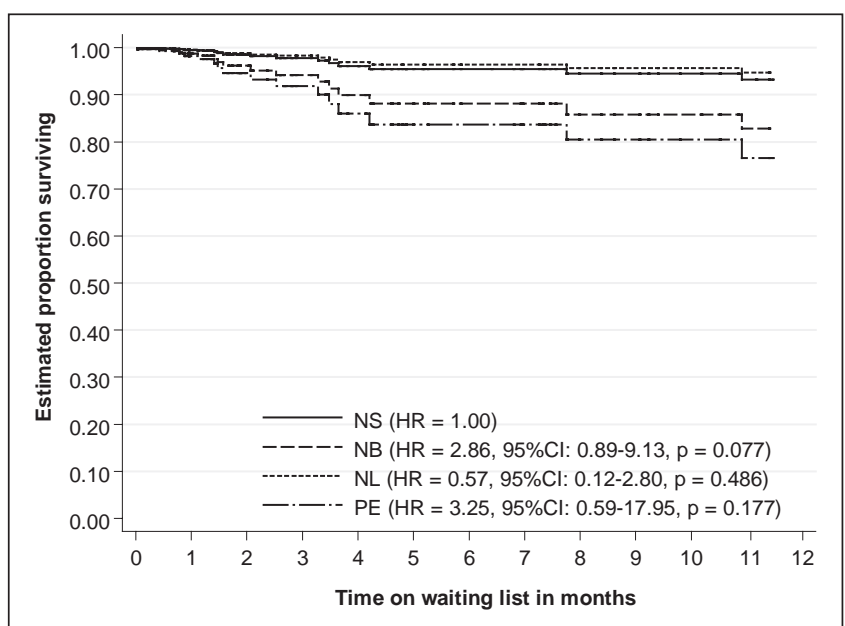

Figure 3) Cox proportional hazards regression estimated wait-list survival according to province of residence, adjusted for Model for End-stage Liver Disease score at the time of wait-list assignment and ABO blood group status $(n=159)$. NB New Brunswick; NL Newfoundland and Labrador; NS Nova Scotia; PE Prince Edward Island

analysis was also conducted to control for the influence of these covariates (5). This analysis did not produce any evidence to indicate that province of residence was associated with differing wait-list survival (Figure 3). A candidate's probability of receiving a liver transplant was also found not to differ significantly according to their province of residence (Fisher's exact $\mathrm{P}=0.798$ ). During the study period, $65.9 \%$ of candidates ( 56 of 85 ) from NS, $70.0 \%$ (28 of 40 ) from NB, $64.3 \%$ (18 of 28 ) from NL and $50.0 \%$ (three of six) of candidates from PE, successfully received a transplant. The Kaplan-Meier estimated median waiting time for the 105 transplant recipients was 105 days (95\% CI 72 days to 140 days). Wait time to transplant was not found to differ significantly among the four provinces (KaplanMeier estimate of median days waiting and 95\% CI: NS 79 days [57 to 112]; NB 116 days [63 to 195]; NL 212 days [39to 281]; PE 178 days [105 to $\infty$ ]; $\log$ rank $\mathrm{P}=0.643$ ), although these estimates appeared to vary considerably among province of residence. When submitted to multivariable analysis, to adjust for the influence of Model for Endstage Liver Disease score and ABO blood group status, wait time to transplant was not found to significantly differ according to province of residence for the 105 candidates who received an allograft (Figure 4). Of note, in view of the small numbers in some of the provincial groups, all of the above analyses were also performed with province of residence dichotomized as being NS or 'other' (NB, NL and PE). These analyses also failed to show any significant differences in waitlist survival, probability of receipt of a transplant or wait time to transplant (results not shown).

\section{DISCUSSION}

In characterizing the cohort of Atlantic Canadians assessed by the Multi-Organ Transplant Program for consideration of first liver transplant in the first five years of activity after its reactivation, the present study uncovered evidence that suggests that there are interprovincial disparities in access to liver transplantation in Atlantic Canada. These disparities appear to be related to factors that act before the initiation of the assessment process because assessment time and the probability of wait-list assignment were not found to differ significantly among the four provinces, nor were wait-list outcomes (wait-list mortality, probability of receiving a transplant or wait time to transplant). To our knowledge, the present study is the first to document this phenomenon with regard to liver transplantation in Canada.

Ideally, individuals in need of liver transplantation, who have a reasonable prospect of recovery post-transplant, should have their access to this treatment determined solely by their medical need and not by

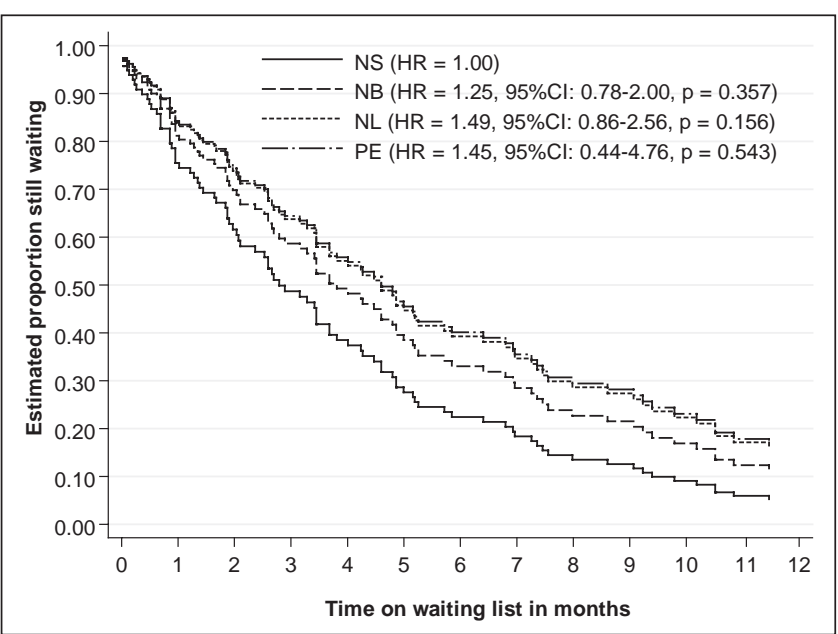

Figure 4) Cox proportional hazards regression estimated waiting time to transplant according to province of residence adjusted for Model for Endstage Liver Disease score at the time of wait-list assignment and ABO blood group status $(n=105)$. NB New Brunswick; NL Newfoundland and Labrador; NS Nova Scotia; PE Prince Edward Island

other factors such as their age, sex, race, financial resources or place of residence. Geographical disparities in access to liver transplantation have been previously documented in countries other than Canada. These studies have predominantly focused on three geographical variables: travel distance to transplant centre; residence in a rural versus urban setting; and residence in different transplant service regions. The latter has been the most frequently reported focus of analysis, and has been fuelled by long-recognized inter-regional differences in wait-list outcomes (ie, mortality, wait time and successful receipt of transplant) in the United States, which have been shown to be due to differences in allograft demand relative to allograft availability among regions (6-8). The United Network for Organ Sharing has attempted to resolve these inequities via modifications to the distribution algorithm; however, a recent study of United Network for Organ Sharing data from 2002 to 2009 documents that considerable differences in candidate mortality, incidence of transplantation and illness acuity at transplant still exist among donation service areas (9). Via their analysis, Yeh et al (9) demonstrated that these inter-regional differences were largely demand driven, and advocated additional changes to allocation policy to permit broader geographical distribution of donor organs.

Inter-regional disparities in liver transplant access are not limited to the United States. Three studies, all published in the same issue of Transplantation in 2003 (10-12), reported on inter-regional differences in access to liver transplantation in France, the United Kingdom and Spain. These studies demonstrated differences in population-based probability of wait-list assignment (12) and liver transplant wait-list outcomes, which included; wait-list mortality (10), probability of transplantation $(10,12)$ and wait time-to-transplantation (10-12) among transplant regions in their respective countries. Proposed explanations of these disparities included inter-regional differences in rates of organ donation and procurement, liver disease prevalence and illness severity of candidates (10-12). Additionally, the Spanish study produced evidence that suggested some regions, particularly those without a transplant centre, had lower rates of referral of individuals with chronic liver disease for consideration of liver replacement (12). In some ways, this latter finding bears similarity to that of the current study.

Greater distance of residence from liver transplant centre, via its imposition of logistical and financial challenges to potential candidates, has been the second most studied geographical variable. An early, but methodologically notable, population-based study evaluating the influence of geographical location on liver transplantation was reported by Tuttle-Newhall et al in 1997 (13). This study used administrative health care data from North Carolina (USA) between 
1988 and 1993, and found that distance of county of residence from transplant centre was a significant independent predictor of the rate of liver transplantation. These investigators also demonstrated, with univariable analysis, that distance from transplant centre had an inverse (dose-response) relationship between level of distance exposure and rate of transplantation. Overall, however, the evidence regarding the influence of residence proximity to transplant centre has been inconsistent. Studies by Ozminkowski et al (14) and McCormick et al (15) both failed to document a significant association between proximity to transplant centre and candidate probability of receiving a liver transplant (although in the later study, residence proximity was found to be an effect modifier of the association between insurance payer and receipt of liver transplant). In an analysis of their first liver transplant referrals between 2002 and 2005, Firozvi et al (16) found that travel time to transplant centre was not associated with the probability of an individual being assigned to the wait list, candidacy assessment time, wait-list survival, probability of receipt of a liver transplant or posttransplant survival. We too, have analyzed the influence of candidate travel time to our transplant centre, and found no association between this geographical variable and candidate assessment time or wait-list survival (5). Therefore, it appears that geographical inequities in liver transplant access cannot be simply explained by distance of residence from transplant centre.

Sharing similar potential impediments to transplant access as proximity to transplant centre, the association between residence in a rural setting and liver transplant accessibility has also been explored. A prominent study, reported by Axelrod et al (17) in 2008, used United Network for Organ Sharing data of transplant wait-list registrations from 1999 to 2004 to evaluate the influence of residency in rural versus urban or suburban areas on wait-list and post-transplant outcomes. The investigators found that residents of rural areas were significantly less likely to be registered for, or receive, a liver transplant. The authors hypothesized that the observed disadvantage could be due to barriers to completing the complex transplant referral and evaluation process faced by rural residents, such as greater travel time and expense, or delay of referral to a specialist. Of note, Axelrod et al (17) found that there were no rural versus urban differences in outcomes postassignment to the wait list. Supporting these latter findings, we have reported an analysis of the influence of rural residency on the wait-list experience of our candidates, which found no evidence that rural residents incurred inferior outcomes relative to their urban/suburban contemporaries once an individual was assigned to our wait list (5). Unlike the study by Axelrod et al, our previous study did not evaluate measures of accessibility before wait-list assignment, a limitation that was, in fact, part of the impetus for our current analysis.

Compared with these previous reports, the present study is unique in that it documents a geographical disparity within a single transplant service region. Additionally, compared with previous studies that have predominantly used wait-list measures (eg, wait-list mortality, probability of transplant receipt or time to transplant) to evaluate the influence of candidate location on liver transplant access, the present study endeavoured to measure access at the level before wait-list assignment (although wait-list measures were also analyzed). As a result of analysis at this level, we have exposed that the subsequent interprovincial differences in wait-list outcomes, such as incidence of wait-list registration and receipt of transplant, appear to have their origins before the start of the transplant assessment process.

The principle findings of the present study, and the exploratory analysis of referrals who died before the liver transplant candidacy assessment could be initiated, suggest a need for the implementation of measures within our service region to increase the recognition and referral of patients with terminal liver diseases for transplantation. The most direct method of achieving this objective would be to increase the hepatology service presence in the Atlantic provinces. This would require either specialist physician recruitment at the provincial/ regional level or provision of satellite clinics to underserved areas by members of our liver transplant service. Additional interventions, such as continuing professional development events or creation of an Internet-based resource outlining the indications and contraindications for liver transplantation, may also facilitate the recognition and timely referral of appropriate candidates for liver replacement by primary care physicians.

One potential limitation of the present study is that it used total provincial population as the denominator of the geographical comparison, rather than provincial liver disease-specific population. The latter would be the optimum denominator to use in the analysis, although, as indicated by Axelrod et al (17), accurately determining the true disease burden in a population can be difficult. As a consequence, the apparent interprovincial differences in the incidence of liver transplant assessment may be explained by differences in the underlying prevalence of liver disease among the four provinces that compose our service region. However, accounting for the observed interprovincial differences would require that the prevalence of liver disease in NS be 1.5 to 2.2 times greater than in the other three Atlantic provinces, a scenario that is not supported by reported provincial age-standardized chronic liver disease mortality rates (per 100,000 residents: NS 6.5, NB 5.1, NL 4.0, PE 8.5) (18). We must also acknowledge that our analysis assumes that our program is the sole provider of liver transplant service to adult residents of the four Canadian Atlantic provinces. If this assumption is violated, and there are a significant number of candidates travelling to transplant programs in other regions, then the observed interprovincial differences in incidence of transplant assessment could be erroneous. Although this scenario may be plausible for NB, where Frenchlanguage patients may prefer to travel to Quebec for liver transplant service, it does not readily explain our observations for the two apparently least served provinces, NL and PE. Indeed, information provided by members of the two adult liver transplant programs in Quebec refutes any important amount of service provision to residents of Atlantic Canada during the five-year study period because only two individuals, both from NB, received a liver transplant from these programs during that time. A final potential limitation concerns our secondary analysis of the five-year wait-list cohort. Because the size of this cohort was modest $(n=159)$ and the number of failure events was small $(n=17)$, our ability to detect interprovincial differences in wait-list survival with this supplementary analysis was constrained. To address this, a complementary analysis, using a dichotomized classification for provincial residential status, was performed in an effort to improve our power to expose any potential geographical difference.

\section{SUMMARY}

In characterizing the cohort of individuals referred to our adult liver transplant service over the five-year period from December 1, 2004 to December 1, 2009, for consideration of candidacy for first liver replacement, we uncovered evidence that suggests significant interprovincial disparities in access to liver transplantation exist in Atlantic Canada. It would appear that the observed differences are a function of relative differences in incidence of referral for transplant assessment because once assessed by our program, there was no evidence of province of residence-related differences in probability of receiving a liver or wait time to transplant. Secondary analyses demonstrated that these interprovincial differences in population-standardized incidence of assessment translated into differences in incidence of wait-list assignment and, ultimately, to receipt of liver transplant. These results suggest a need for the implementation of measures within our service region to increase the recognition and referral of patients with terminal liver diseases for liver transplantation.

ACKNOWLEDGEMENTS: Dr Renfrew expresses his gratitude to Catherine Guimont, Mary Jane MacNeil and Terry Reardon for their provision of guidance and assistance, which greatly facilitated the creation of 
the data set on which this study was based. Dr Renfrew also thanks Dr Marc Bilodeau of the University of Montreal and Dr Murad Alfiffry of McGill University for providing information regarding the provision of liver transplant services to residents of the Atlantic Provinces by their respective programs.

\section{REFERENCES}

1. Statistics Canada. Population and dwelling counts, for Canada, provinces and territories, 2006 and 2001 censuses - Population and Dwelling Count Highlight Tables; 2007 [updated 2007; cited October 17, 2011]; Statistics Canada Catalogue no. 97-550. XWE2006002. Ottawa. Released March 13, 2007. <www12.statcan. $\mathrm{ca} /$ english/census06/data/popdwell/Table.cfm? $\mathrm{T}=101 \& \mathrm{SR}=1 \& \mathrm{~S}=0 \&$ $\mathrm{O}=\mathrm{D} \& \mathrm{RPP}=25 \& \mathrm{PR}=0 \& \mathrm{CMA}=0>($ Accessed October 17, 2011).

2. Wilson EB. Probable inference. The law of succession and statistical inference. J Am Statist Assoc 1927;22:209-12.

3. Rothman KJ. Analyzing simple epidemiological data. Epidemiology: An Introduction. New York: Oxford University Press Inc; 2002:130-43.

4. Renfrew PD, Quan H, Doig CJ, Dixon E, Molinari M. The Model for End-stage Liver Disease accurately predicts 90-day liver transplant wait-list mortality in Atlantic Canada. Can J Gastroenterol 2011;25:359-64.

5. Renfrew PD, Molinari M. Rural residency and the risk of mortality while waiting for liver transplantation. Clin Transpl published online December 30th, 2011. DOI:10.1111/j.1399-0012.2011.01576.x.

6. Ubel PA, Caplan AL. Geographic favoritism in liver transplantation - unfortunate or unfair? N Engl J Med 1998;339:1322-25.

7. Institute of Medicine Committee on Organ Procurement and Transplantation Policy. Organ Procurement and Transplantation: Assessing Current Policies and the Potential Impact of the DHHS Final Rule. Washington, DC: National Academy Press; 1999.
8. Ellison MD, Edwards LB, Edwards EB, Barker CF. Geographic differences in access to transplantation in the United States. Transplantation 2003;76:1389-94.

9. Yeh H, Smoot E, Schoenfeld DA, Markmann JF. Geographic inequity in access to livers for transplantation. Transplantation 2011;91:479-86.

10. Roudot-Thoraval F, Romano P, Spaak F, Houssin D, Durand-Zaleski I. Geographic disparities in access to organ transplant in France. Transplantation 2003;76:1385-8.

11. Rudge CJ, Fuggle SV, Burbidge KM. Geographic disparities in access to organ transplantation in the United Kingdom. Transplantation 2003;76:1395-8.

12. Miranda B, Canon J, Cuende N, Garrido G, Naya MT, Fernandez-Zincke E. Disparities in access to liver transplantation in Spain. Transplantation 2003;76:1398-403.

13. Tuttle-Newhall JE, Rutledge R, Johnson M, Fair J. A statewide, population-based, time series analysis of access to liver transplantation. Transplantation 1997;63:255-62.

14. Ozminkowski RJ, Friedman B, Taylor Z. Access to heart and liver transplantation in the late 1980s. Med Care 1993;31:1027-42.

15. McCormick PA, O'Rourke M, Carey D, Laffoy M. Ability to pay and geographical proximity influence access to liver transplantation even in a system with universal access. Liver Transpl 2004;10:1422-7.

16. Firozvi AA, Lee CH, Hayashi PH. Greater travel time to a liver transplant center does not adversely affect clinical outcomes. Liver Transpl 2008;14:18-24.

17. Axelrod DA, Guidinger MK, Finlayson S, et al. Rates of solid-organ wait-listing, transplantation, and survival among residents of rural and urban areas. JAMA 2008;299:202-7.

18. Statistics Canada. Table 102-0552 - Deaths and mortality rate, by selected grouped causes and sex, Canada, provinces and territories. annual [updated annual October 18, 2011]. <www5.statcan.gc.ca/ cansim/a01 lang=eng $>($ Accesed November 26, 2011). 


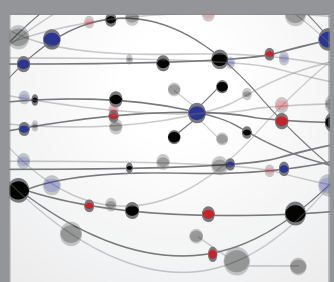

The Scientific World Journal
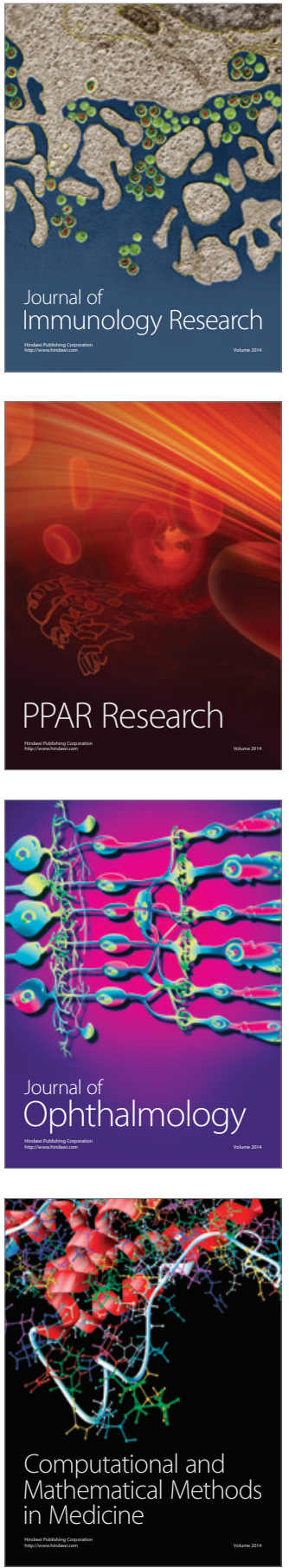

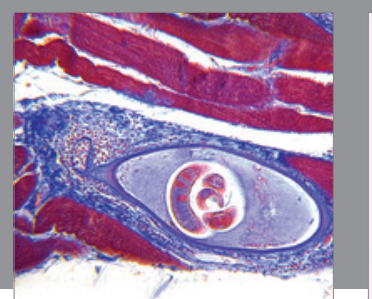

Gastroenterology Research and Practice

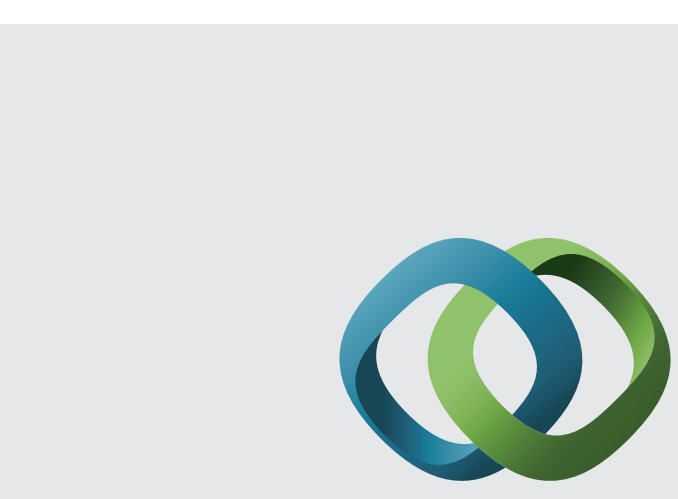

\section{Hindawi}

Submit your manuscripts at

http://www.hindawi.com
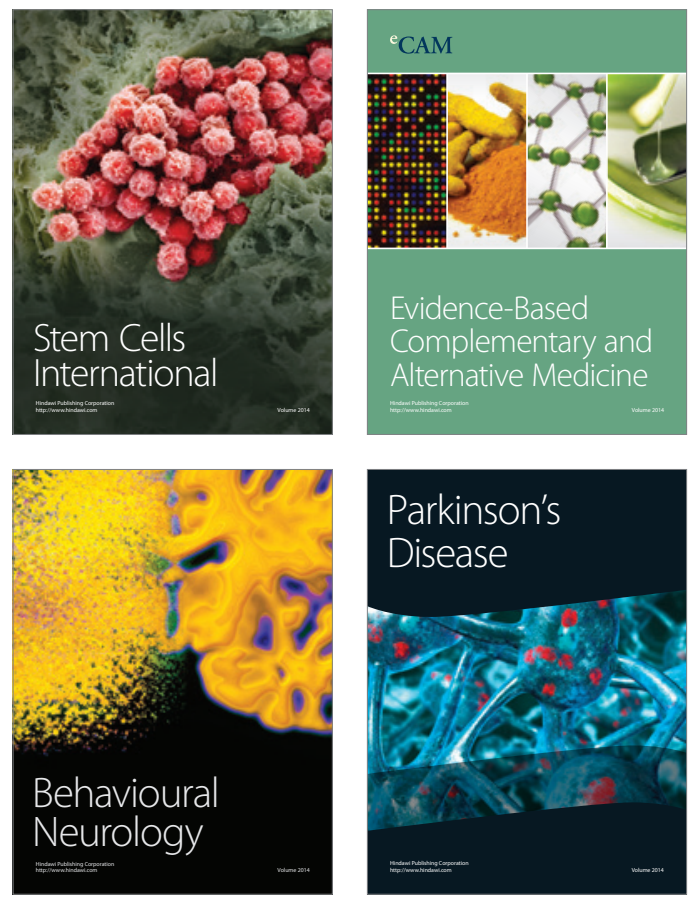
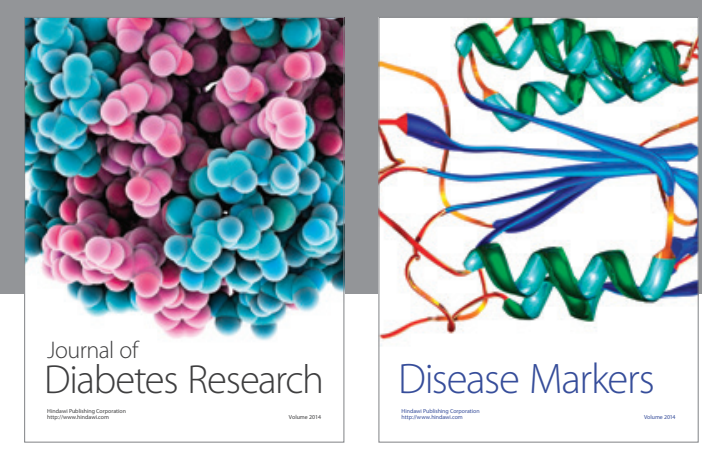

Disease Markers
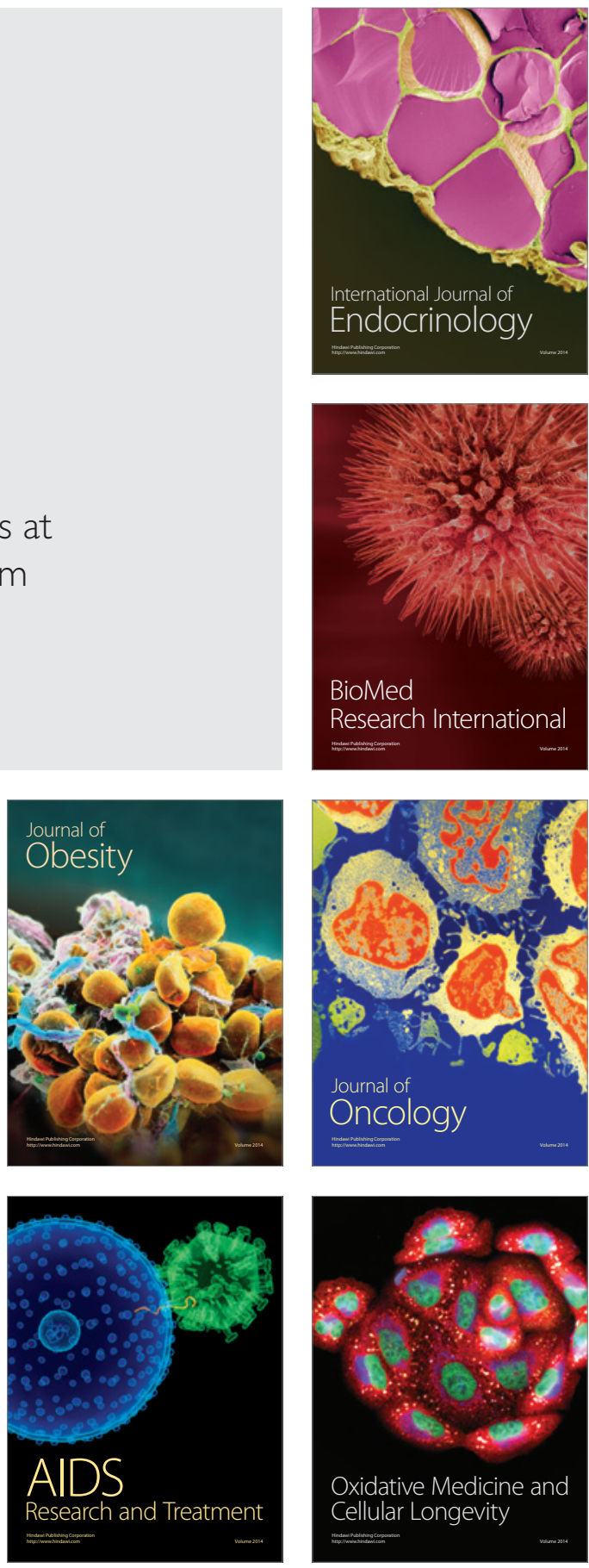